


Revista Internacional de Comunicación y Desarrollo (RICD), 4(15), 2021. ISSN-e: 2386-3730

https://doi.org/10.15304/ricd.4.15.8179

Proyectos

\title{
O proxecto do Campus da Cidadanía
}

Nieves Lagares Diez

Comisionada para o Campus da Cidadanía, Universidade de Santiago de Compostela, España

mnieves.lagares@usc.es

Estudantes no campus universitario.

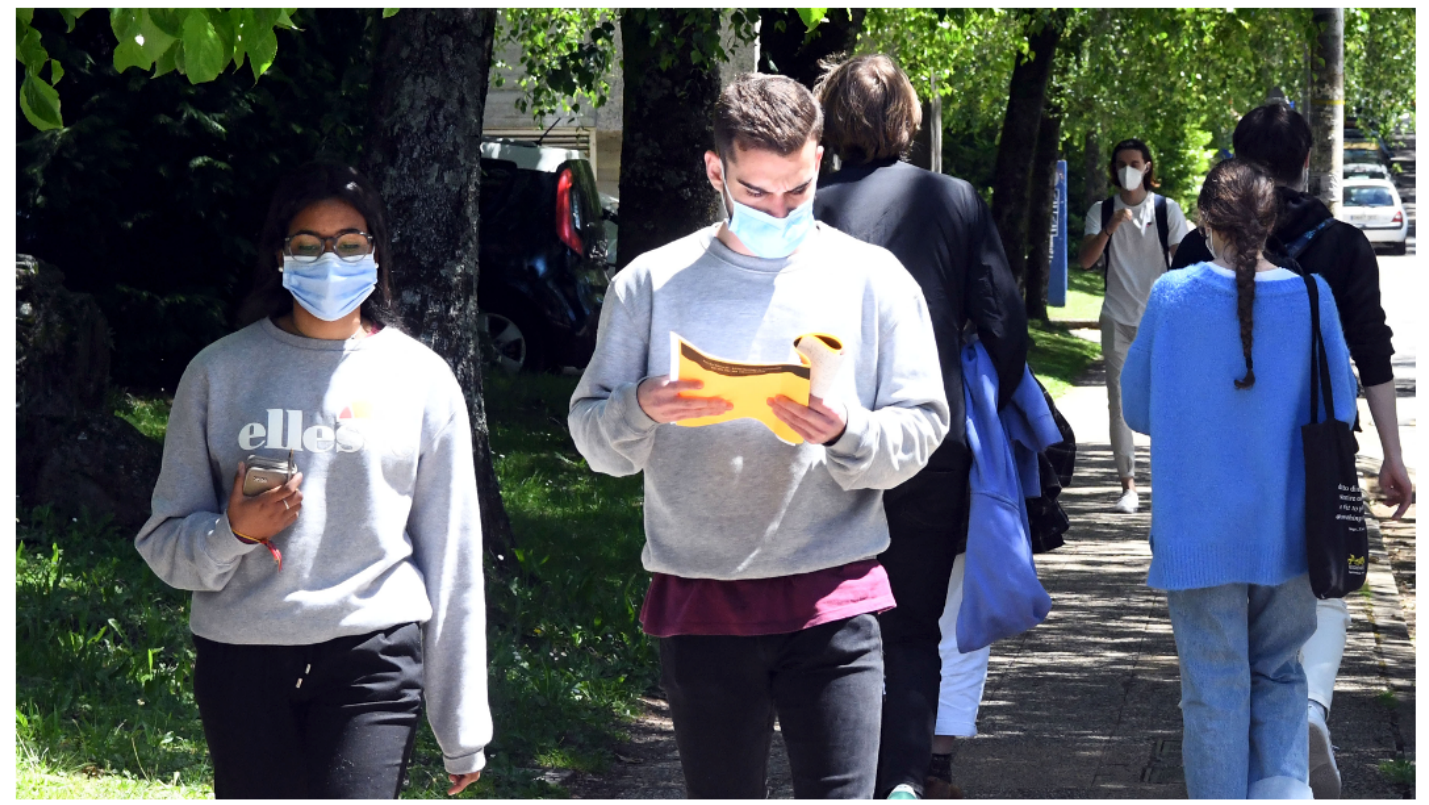

\section{INTRODUCCIÓN}

O proxecto Campus da Cidadanía ten por obxecto construír un espazo de encontro da investigación e do ensino-aprendizaxe en ciencias sociais e humanas na procura de sinerxías e aproveitamentos comúns que podan dar orixe a novas dinámicas de investigación nestas áreas.

o Campus concíbese coma un espazo, non necesariamente físico, no que ocorren cousas que afectan á actividade investigadora e á actividade docente nas áreas de ciencias sociais e humanas; no que os verdadeiros protagonistas son os investigadores, e onde a investigación e o ensino se transforman. Nese espazo, o papel da dirección do Campus redúcese a promover, coordinar, dinamizar, pero os actores do Campus son os investigadores e a súa investigación.

Nun contexto cambiante, complexo e competitivo, o Campus ten unha vocación transformadora da propia investigación nestas disciplinas co fin de promover cambios que produzan resultados 
medibles, e para iso é imprescindible o promover acordo dos investigadores na lóxica dos cambios. Non se trata de cambiar o contido da investigación senón de encontrar as rutas para colocar a nosa investigación no mundo e mellorar a súa estrutura e o seu impacto.

\section{DIMENSIÓN, COOPERACIÓN, ESTRATEXIA}

Dende esta concepción transformadora, dimensión, cooperación e estratexia son termos claves para entender o que persegue o Campus.

A dimensión, o tamaño dos nosos grupos lastra a construción en torno a eles de estruturas profesionalizadas de apoio, o que fai que todo o traballo burocrático e de xestión dos proxectos recaia sobre os investigadores. Pero tamén limita o acceso a proxectos diversos, xa que cada proxecto require a implicación da maioría dos membros do grupo; ou o acceso a proxectos europeos; e mesmo limita a existencia de varios IPs.

Redimensionar os grupos de investigación é unha necesidade, que pasa por clasificar os grupos en función de criterios obxectivos tales como número de membros, de sexenios, de publicacións, de teses, de proxectos, de recursos, etc. (en valores absolutos e ratios) pero, dacordo cos criterios da nosa Universidade para a definición dos grupos ${ }^{1}$, tamén pasa por facer do grupo de investigación "unha unidade organizativa estable, con masa crítica e recursos suficientes para asegurar o desenvolvemento dunha actividade investigadora competitiva e continuada, apoiada nunha capacidade de financiamento sostible". O Campus, a medio prazo, debe ser o espazo no que reconstruír e redimensionar os grupos e os equipos de investigación.

A cooperación consiste no apoio entre grupos e unidades de investigación na procura de obxectivos comúns, colectivos, ou singulares, dun grupo concreto. A colaboración ten catro ámbitos fundamentais: os contactos, a experiencia, os coñecementos e o persoal. A construción de bases de datos nas que se poda acceder sistemáticamente a estes contidos, e a xeración dunha cultura de cooperación entre os grupos está a ser un obxectivo fundamental do Campus.

Algúns destes elementos xa están nas bases de datos dos grupos, outros terán que incorporarse. A USC é unha caixa enorme de oportunidades e recursos; o noso obxectivo, e a iso destinamos unha boa parte deste tempo, é que todos os investigadores saiban onde están, teñan acceso a eles, e que xeremos, entre todos e todas unha cultura de que os recursos de cadaquén deben ser útiles para todos. Non renunciamos á competición, pero creemos que é posible construír unha nova cultura da competición, moito mais cooperativa.

A estratexia é a base da investigación moderna; constrúe os fins, obxectivos, e os camiños polos que se debe desenvolver a investigación.

A lóxica tradicional das nosas disciplinas é de natureza dispersa. A USC ten magníficos investígadores, con currículos importantes, que nunca tiveron unha estratexia de investigación. Moitos dos nosos investigadores seniors seguen a traballar de maneira individual, e xúntanse, en todo caso, para conseguir proxectos ou facer unha publicación, hoxe con uns, mañá con outros, pero nunca planearon unha estratexia colectiva e estable de investigación. A febleza histórica dos nosos grupos provén desta orixe, pero estase a reconducir de maneira importante.

o Campus debe ser o espazo natural para o deseño desta estratexia, que debe ter, alomenos, tres dimensións: unha dimensión unitaria do propio campus, unha dimensión colectiva que abrangue ás diversas unidades de investigación (grupos, agrupacións, etc.) e unha dimensión individual que faga referencia aos modelos e tendencias de implicación e incorporación dos investigadores nos grupos. 
E todas estas cousas tamén requiren dunha nova cultura do que significa o valor da investigación e mesmo o propio significado do investigador nas nosas disciplinas.

Estes tres aspectos, dimensión, cooperación, estratexia, constitúen o núcleo do cambio que se debe producir na nosa investigación, pero, como vimos explicando, ningún deles será posible se non creamos unha cultura investigadora que avale estes cambios.

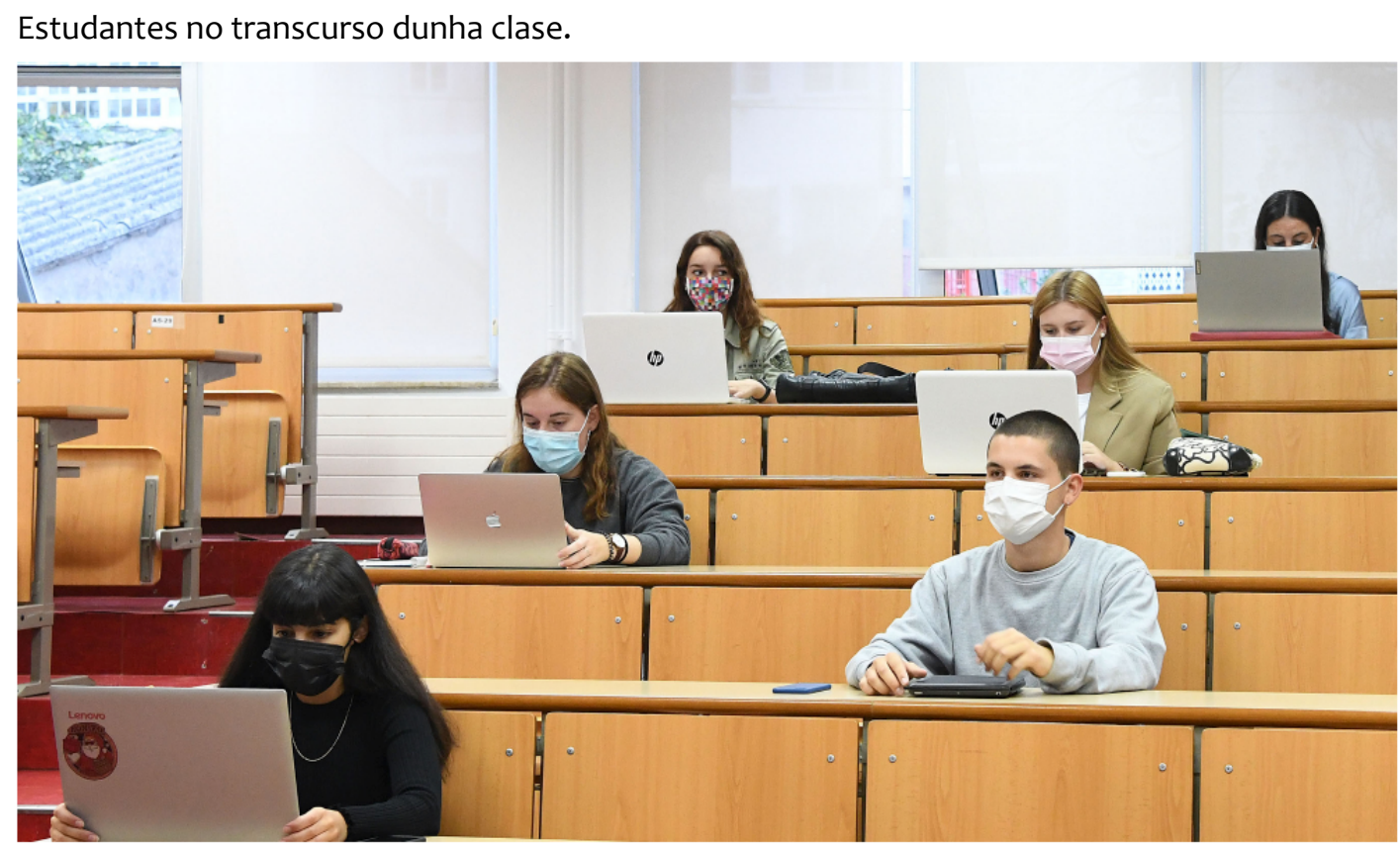

\section{UNHA NOVA CULTURA INVESTIGADORA}

Lonxe do que moitos pensan, a cultura é o maior espazo de resistencia aos cambios. Nas nosas áreas, temos pasado dunha resistencia e menosprezo do traballo colectivo a unha aceptación do mesmo, pero aínda falta aprecialo definitivamente. Un traballo no que se require a colaboración de varios autores parécenos que ten menos valor que o que fai un individuo. Mesmo temos unha certa indisposición a non saber que é o que fixo cadaquén nun artigo. Non engulimos o termo "colectivo".

A nosa lóxica vai do individual ao colectivo, en vez de ir do colectivo ao individual. A nosa liña individual de traballo preexiste á colectiva que case sempre, cando se da, constrúese coma unha amalgama onde encaixan, daquela maneira, as liñas individuais. Froito deste camiño, os proxectos "agrupativos" son sempre febles.

Construír unha nova cultura require incentivar, premiar, o traballo na outra dirección. E aí necesítase a complicidade da Xunta de Galicia, e da USC, para crear rutas propias das nosas disciplinas que conduzan a resultados semellantes aos das outras Ciencias, sen que haxa que copiar, exactamente, as rutas deles. As compoñentes desta nova cultura son básicas: valorar a cooperación dentro da USC, os grupos competitivos, o traballo colectivo interno, a estabilidade da investigación e os resultados das liñas.

Pero para incentivar esta nova cultura, necesítase crear incentivos reais e diferentes aos das outras Ciencias. Os grandes incentivos dos grupos de Ciencias teñen sido dous: os proxectos competitivos e o crecemento dos cadros de PDI (persoal docente e investigador) a través de figuras específicas. Nas nosas disciplinas esas figuras terán sempre unha dimensión ridícula e os proxectos 
competitivos non son tan importantes, economicamente falando (un grupo pode conseguir a través de proxectos competitivos unhas decenas de miles de euros para tres anos, e por un contrato cunha administración ou empresa centenares de miles).

¿Onde están entón eses incentivos?

Podemos premiar os esforzos nesta dinámica incorporando valoracións referidas a estes esforzos (valorar a pertenza a un grupo de referencia, sacar as bolsas de colaboración dos estudantes non para os departamentos senón para grupos competitivos, ou impedir que unha comisión poda valorar mais un artigo por ser individual; e mesmo permitir a existencia de varios IP dentro dos grupos, ou de equipos dentro dos grupos, etc.)

E podemos acordar coa Xunta a creación de rutas propias para reincorporar investigadores, e mesmo na USC crear criterios de investigación alternativos aos de experimentalidade, tan propios das outras ciencias.

Incluso podemos, como universidade, favorecer a creación de Contratos e Programas Estables de Investigación, obxectivamente avaliados, como se está a implantar.

0 certo é que a creación dunha nova cultura investigadora necesita incentivos selectivos, que reforcen a quen siga esa ruta e promova a incorporación de novos actores. Doutro xeito seguiremos no puro voluntarismo. Pero non pode ser construída, e aquí está o erro habitual, coma unha imposición do modelo de ciencias. Ten que ser unha ruta propia, á que sabemos que algúns investigadores non poderán xa incorporarse, ou terán modelos de incorporación non definitivos nin exclusivos; pero na que deben situarse xa todos os novos investigadores. Dito doutro xeito, non se pode seguir a premiar o individualismo, por moi atractivo que resulte.

Biblioteca da Facultade de Xeografía e Historia.

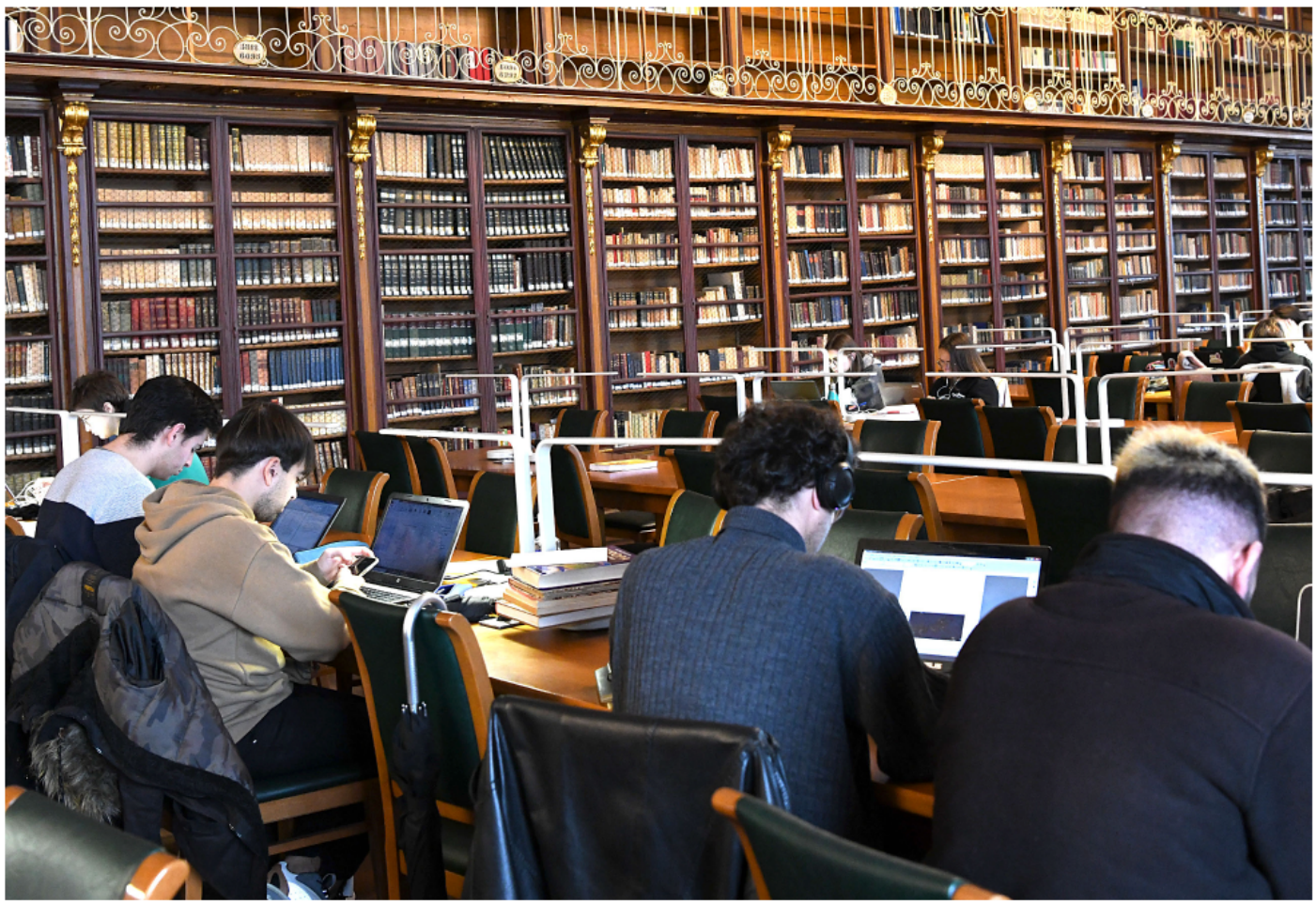




\section{OS OBXECTIVOS DO CAMPUS DA CIDADANÍA NO ÁMBITO DA INVESTIGACIÓN}

Como sinalábamos ao principio, o Campus da Cidadanía ten como un dos seus obxectivos fundamentais construír un espazo de encontro da investigación en ciencias sociais e humanas na procura de sinerxías e aproveitamentos comúns que podan dar orixe a novas dinámicas de investigación nestas áreas.

Estas dinámicas non son outras que as que están a mobilizar a competitividade da investigación en países máis desenvolvidos neste terreo. Facer a nosa investigación máis competitiva, internacionalizala, mellorar os índices de impacto, liderar proxectos transnacionais.

Os investigadores nestas áreas, especialmente en Ciencias Sociais, sempre teimamos co feito de que a nosa é unha investigación localmente referenciada e, xa que logo, presenta algunhas dificultades a estes procesos; e é certo. Pero tamén é certo que existen nos nosos contornos, grupos que teñen no espazo internacional a súa única referencia, e publican maioritariamente en inglés. A incorporación a estas dinámicas non pode ser formulada coma unha vocación senón coma unha necesidade dentro dunha estratexia colectiva da USC

Parece que a estrutura e as capacidades da investigación van unidas. Se como temos sinalado as debilidades naceron da dispersión orixinaria, un modelo estrutural que mitigue, e mesmo utopicamente remate, con esa dispersión fortalecería a nosa investigación.

Esa é hoxe a folla de ruta das políticas de investigación en Europa, en España e en Galicia. Mentres non se diga o contrario, estamos abocados a conducirnos nesa dirección. E nese sentido, os primeiros obxectivos do Campus deben ter carácter estrutural. Desde este punto de vista estrutural, o Campus ten, cando menos, cinco obxectivos específicos:

a. Servir de espazo no que emerxan, se ordenen e se consoliden as estruturas científicas das nosas áreas.

b. Servir de espazo para a produción de sinerxías e de cooperación entre os grupos e mesmo para a redimensionalización dos mesmos.

c. Servir de espazo para que o papel dos institutos de investigación (IDEGA, ICE, etc.) adquira unha nova dimensión e penetre máis o tecido investigador da USC.

d. Servir de espazo para a creación de sinerxías cara a encher baleiros formativos, especialmente no nivel de máster ou doutoramento que implique as capacidades de varios grupos.

e. Servir de espazo de difusión da investigación das nosas áreas en tres niveis: difusión na sociedade (estratexia de comunicación); difusión científica (publicacións, traducións, etc.); difusión en eventos (congresos, foros, etc.). 
Estudantes antes dun exame.

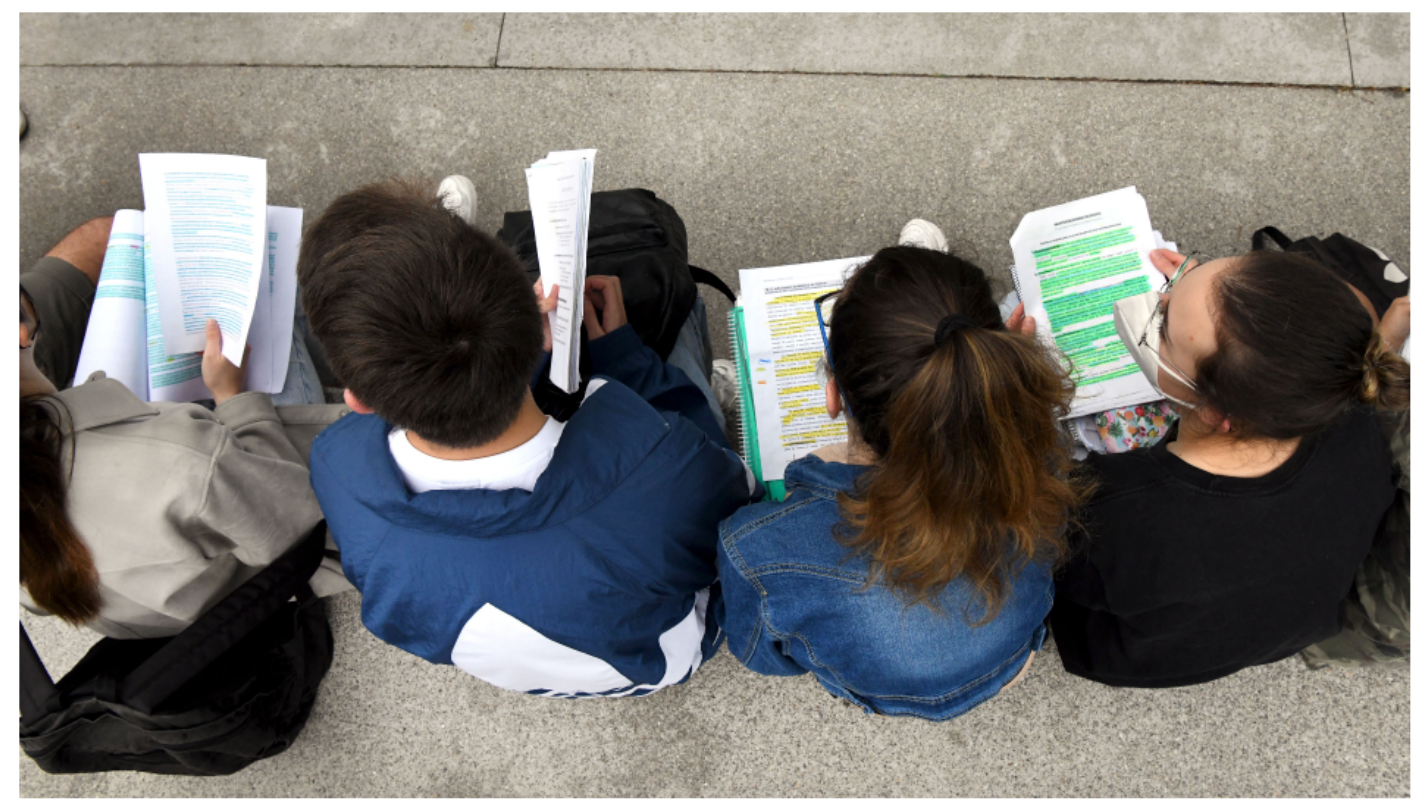

No que se refire ó primeiro obxectivo, fortalecer as estruturas científicas das nosas áreas, a convocatoria de manifestacións de interese, lanzada pola vicerreitoría de investigación en colaboración co Campus, en outubro do 2020, tería como finalidade acoller propostas, promovidas dende os grupos de investigación, de identificación e desenvolvemento de áreas estratéxicas de I+D+I. A presentación de 6 propostas, tres no eido das Ciencias Sociais e tres no ámbito das Humanidades serviu de base para a discusión e debate da posible creación de dous centros de investigación (un en cada unha das grandes áreas) nos que aínda se está a traballar.

De xeito simultáneo, a busca de cooperación entre os grupos vai orientada en dúas direccións: a de internacionalizar e incrementar o impacto da investigación dos grupos, ademais de atopar vías de financiación alternativas ás das administracións estatais e autonómicas. Neste contexto nos últimos catro anos, iniciouse un proceso de, por unha banda, identificación de capacidades dos grupos de investigación (fundamentalmente daqueles considerados de referencia competitiva e de potencial crecemento) e por outra, de busca de oportunidades dentro do marco do novo programa Horizonte Europa. Como resultado deste traballo, coa participación e implicación de tódolos grupos RC e PC, tense elaborado fichas de capacidades que permiten ver as potencialidades dos grupos en relación con certos topics e as posibles sinerxías entre eles en torno a espazos e liñas comúns de investigación. Agora mesmo, a diagnose de varias liñas está a permitir articular a posible coordinación ou participación en un par de proxectos da próxima convocatoria europea.

É un feito que non tódolos grupos, nin tódolos investigadores se atopan no mesmo punto de partida, a pesar disto a exploración de vías distintas de colaboración e participación en redes e consorcios europeos forma parte da lóxica deste proceso que ten por obxectivo dar estabilidade e redimensionar os grupos como unidades da investigación.

Nesta definición de novas estruturas e liñas de investigación a USC está a afrontar o reto de resituar o papel dos institutos xa existentes no ámbito do Campus da Cidadanía, de tal xeito que afronten novos desafíos que forman parte da investigación e dos ámbitos de especialización que estamos tratando de perfilar. 
No relativo ao obxectivo de innovar en procesos formativos, o aproveitamento da colaboración entre áreas de coñecemento moi distintas deu como resultado a proposta dun título de Máster oficial en Cooperación Internacional ao Desenvolvemento, impulsado dende o Campus da Cidadanía, que xurde arredor de 5 departamentos da USC e na que se vinculan en total nove departamentos. A proposta, en vías de tramitación, supón a transformación dun título propio da Universidade de longa traxectoria e ampla demanda, único no ámbito do SUG (Sistema Universitario Galego), que ven a cubrir un ámbito de especialización de carácter multidisciplinar e cunha importante dimensión profesional.

0 último obxectivo mencionado afecta a difusión da actividade de grupos e investigadores do Campus. A difusión, na súa dimensión estritamente comunicativa, pasa pola comunicación interna, en dirección à propia comunidade universitaria, moitas veces descoñecedora dos avances da investigación dos seus grupos, e pola comunicación cara a fóra, en dirección á sociedade e aos grupos de interese da produción científica e académica da universidade. Neste sentido, a recente creación da web do Campus, dá visibilidade ao feito e a quen o fai, e serve de espazo de encontro para posibles e futuras colaboracións dentro e fóra da USC.

0 traballo de difusión/divulgación científica, ben a través de publicacións, ben a través de conferencias ou foros, contribúe non só a facer accesible a tódolos públicos o coñecemento científico senón tamén a transferencia dese coñecemento, a súa aplicabilidade dando solucións a problemas concretos que se demandan dende a sociedade. Na web do Campus da Cidadanía encóntrase, nos apartados de recursos e stories, moito do traballo que os grupos de investigación realizan dentro do ámbito da transferencia do coñecemento, como aquela parte dos resultados da investigación que ten un carácter instrumental.

Estes cinco obxectivos conducen en si mesmos a un novo deseño das estruturas de investigación nas nosas áreas e, só son posibles gracias á coordinación cos Servizos Xerais de Investigación da propia Universidade.

\section{NOTAS}

Nieves Lagares Diez é profesora titular de Ciencia Política e da Administración, na Universidade de Santiago de Compostela. Experta no estudo da formación e organización dos partidos políticos, nas cuestión relativas ao liderazgo e na mercadotecnia política.

Contacto: mnieves.lagares@usc.es

1

Criterios para a redefinición do catálogo de investigadores e grupos de investigación (2009). 